\section{UJMM

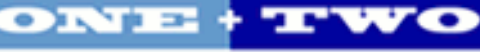

Volume 2 | 2010 Spring

\section{Undergraduate Journal of Mathematical}

Modeling: One + Two

2010

\title{
Calculating the Time Constant of an RC Circuit
}

Sean Dunford

University of South Florida

Advisors:

Arcadii Grinshpan, Mathematics and Statistics

Gerald Woods, Physics

Problem Suggested By: Gerald Woods

Follow this and additional works at: https://digitalcommons.usf.edu/ujmm

Part of the Mathematics Commons

UJMM is an open access journal, free to authors and readers, and relies on your support: Donate Now

\section{Recommended Citation}

Dunford, Sean (2010) "Calculating the Time Constant of an RC Circuit," Undergraduate Journal of Mathematical Modeling: One + Two: Vol. 2: Iss. 2, Article 3.

DOI: http://dx.doi.org/10.5038/2326-3652.2.2.3

Available at: https://digitalcommons.usf.edu/ujmm/vol2/iss2/3 


\title{
Calculating the Time Constant of an RC Circuit
}

\author{
Abstract \\ constant using calculus.

\section{Keywords} \\ Time Constant, RC circuit, Electronics

\section{Creative Commons License} \\ (c) (i) ()
}

In this experiment, a capacitor was charged to its full capacitance then discharged through a resistor. By timing how long it took the capacitor to fully discharge through the resistor, we can determine the RC time

This work is licensed under a Creative Commons Attribution-Noncommercial-Share Alike 4.0 License. 


\section{TABLE OF CONTENTS}

Problem Statement

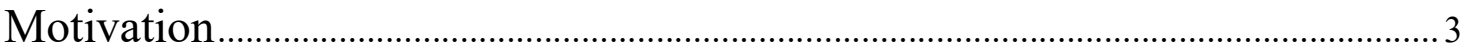

Mathematical Description and Solution Approach .....................................................

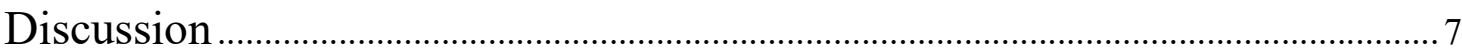

Conclusion and Recommendations........................................................................

Nomenclature

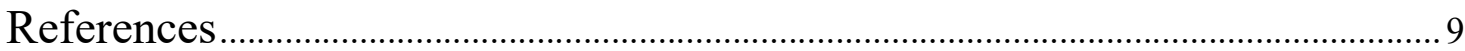

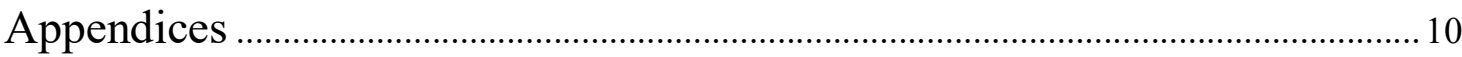




\section{PROBLEM STATEMENT}

Using calculus, determine the time constant $\tau$ of an RC circuit for a recorded time with an initial charge on the capacitor of $7 \mu f$, and a voltage of 30 volts.

\section{MOTIVATION}

This project and derivation is designed to acknowledge the value of a circuit's RC time constant. Knowing the time constant of an RC circuit can allow it to be used as a hardware filter. It can be utilized to only react to certain changes within the circuit. For instance windshield wiper speed settings in modern cars are controlled by RC circuits. They allow a lower voltage to reach the windshield wipers which makes them move slower. Electronic instruments, washing machines, children's toys, and many other pieces of technology all contain RC circuits. (Koehler,1)(Sheets. 1)

\section{MATHEMATICAL DESCRIPTION AND SOLUTION APPROACH}

After setting up the circuit to match the schematic and picture of circuit, we place a max charge on the circuit plate that is equal to that of the power supply (30 volts). The capacitance is supplied by a decade box and is given as $7 \mu F$ (microfarads). The resistance is given by the DMM resistor as $10 M \Omega$ (megaohms). Our resistor is also used to measure voltages at specific variable times. Charging the capacitor takes less than a second. We can determine the charge and current equations by considering Kirchhoff's voltage law. It states that the summation of the charges on all the pieces within a loop will always equal zero at any time $t$ (Serway,785), i.e.

$$
\varepsilon+\Delta V_{\text {resistor }}+\Delta V_{\text {capacitor }}=0 \text {. }
$$


The emf $\varepsilon$ of the battery is taken to be 30 volts, the current at some instant is represented by $I$, the potential drop across the resistor is $-I R$, the magnitude of the charge on the capacitor at some instant is $Q$, the potential drop across the capacitor plates is shown as $-Q / C$ (Serway, 745/767). We can now rewrite (1) as

$$
\varepsilon-I R-\frac{Q}{C}=0
$$

Any time before the capacitor has a charge, $Q=0$ and (2) becomes

$$
I=\frac{\varepsilon}{R}
$$

Once the capacitor has reached the full voltage of the power supply $I=0$ since charge no longer flows in the circuit. When this happens, (2) becomes

$$
Q=C \varepsilon
$$

Current $I$ is the change in charge over the change in time (Serway,753), i.e.

$$
I=\frac{d Q}{d t}
$$

By substituting (5) into (2) we have,

$$
\varepsilon-\left(\frac{d Q}{d t}\right) R-\frac{Q}{C}=0
$$

and implies that

$$
\frac{d Q}{\varepsilon C-Q}=\frac{d t}{R C}
$$

If we integrate both sides, we achieve

$$
\int_{Q\left(t_{0}\right)=0}^{Q\left(t_{f}\right)}\left(\frac{1}{\varepsilon C-Q(t)}\right) d Q(t)=\frac{1}{R C} \int_{t_{0}=0}^{t_{f}} d t
$$

which evaluates to

$$
\ln \left|\varepsilon C-Q_{f}\right|-\ln |\varepsilon C|=\ln \left|\frac{\varepsilon C-Q_{f}}{\varepsilon C}\right|=-\frac{t_{f}}{R C} .
$$

If $x=y$, then $e^{x}=e^{y}$ and (8) becomes 


$$
e^{\ln \left|\frac{\varepsilon C-Q_{f}}{\varepsilon C}\right|}=\frac{\varepsilon C-Q_{f}}{\varepsilon C}=e^{\left(-\frac{t}{R C}\right)}
$$

and simplifies to

$$
Q(t)=Q_{f}=\varepsilon C\left(1-e^{-\frac{t}{R C}}\right)
$$

Note that we may substitute (10) into (5) to get an equation for current:

$$
I=\frac{d Q}{d t}=\frac{d}{d t}\left[\varepsilon C\left(1-e^{-\frac{t}{R C}}\right)\right]=\frac{\varepsilon}{R} e^{-\frac{t}{R C}}
$$

Our main goal is to determine the exact value of the time constant $\tau=R C$. At time $t=\tau$, equation (10) tells us that

$$
Q(\tau)=Q(R C)=\varepsilon C\left(1-e^{-\frac{R C}{R C}}\right)=\varepsilon C\left(1-\frac{1}{e}\right)
$$

We can determine the time constant more accurately by considering similar equations for the discharging process. At time $t=\tau$ the emf $\varepsilon$ from the battery is present on the plates of the capacitor. After the battery is disconnected from the circuit, the emf on the plates begins to dissipate. This discharging equation for $Q$ is similar to (2) and is given by

$$
I R-\frac{Q}{C}=0
$$

which via (11) reduces to

$$
Q(t)=R C\left(\frac{\varepsilon}{R} e^{-\frac{t}{R C}}\right)=\varepsilon C e^{-\frac{t}{R C}}
$$

During this discharge process $\varepsilon$ is constant as the battery is disconnected from the circuit. Also, note that the current switches direction away from the capacitor becoming negative. This transforms (5) into

$$
I=-\frac{d Q}{d t}
$$

In light of equation (14) and (15) we still get the same positive current equation as in (11)

$$
I=-\frac{d Q}{d t}=-\frac{d}{d t}\left[\varepsilon C e^{-\frac{t}{R C}}\right]=\frac{\varepsilon}{R} e^{-t / R C}
$$


During the discharge process, voltages were recorded at various time intervals (see Table 1.2 in the Appendix). Graphing the voltage versus time yielded an exponentially decaying graph. To determine the time constant, we must establish a linear relationship $(y=m x+b)$ of voltage and time. If we consider that relationship between charge and voltage

$$
V=\frac{Q}{C}
$$

where $V$ is voltage, $Q$ is charge and $C$ is capacitance, (14) becomes

$$
V(t)=\frac{Q(t)}{C}=\varepsilon e^{-\frac{t}{R C}}
$$

By taking the natural logarithm of both sides of (18), we establish a linear relationship between $\log [V(t)]$ and time $t$ :

$$
\log [V(t)]=\log \left[\varepsilon e^{-\frac{t}{R C}}\right]=-\frac{1}{R C} t+\log \varepsilon
$$

Using linear regression implemented in Excel (Graph 2.1), we find that

$$
\log [V(t)] \approx-0.0205342 t+3.39561
$$

which means

$$
\tau=R C \approx 48.6993 \quad \text { and } \quad \varepsilon \approx 29.8329 .
$$

From (18) we know that the voltage is $e^{-1} \approx 37 \%$ of the initial charge during the charging process. Since we know the initial value is equal to $\varepsilon=30 v$, the emf of the battery the capacitor at time $\tau$ will read

$$
30\left(e^{-1}\right) \approx 11.0364 \text { volts. }
$$

Charging the capacitor and timing how long it took to reach our target value of 11.04 volts yielded the experimental value of RC. 


\section{DISCUSSION}

This project found that the RC time constant of our circuit was 48.7 seconds. The objective of the project was met. According to our theoretic results, the voltage at the time should be 11.04 volts which was shown in Graph 1.1 to have occurred (see Appendix). With this time constant we could direct certain frequencies of voltages through our circuit and control a multitude of different objects.

\section{CONCLUSION AND RECOMMENDATIONS}

This project exploited the use of calculus to determine the RC time constant of a circuit. The time constant is a time in which it takes the capacitor to lose $63 \%$ of its initial charge. With a maximum initial voltage across a set of capacitor plates, a capacitance of $7 \mu F$ and a $10 M \Omega$ resistor, we calculated the time constant to be around 48.7 seconds. Our theoretical results were compared with the experimental quantities. We measured the time constant by using a stop watch to record the time it takes for the voltage to drop from $30 \mathrm{~V}$ to a target voltage of $11.04 \mathrm{~V}$. 


\section{NOMENCLATURE}

\begin{tabular}{|cll|}
\hline Symbol & \multicolumn{1}{c|}{ Name } & \multicolumn{1}{c|}{ Measured Units } \\
\hline$\tau$ & Time Constant & Seconds (sec) \\
\hline$C$ & Capacitance & Farads (f) or Microfarads $(\mu \mathrm{f})$ \\
\hline$V$ & Voltage & Volts $(\mathrm{V})$ \\
\hline$R$ & Resistance & Megaohms $(\mathrm{M} \Omega)$ \\
\hline$\varepsilon$ & Emf of Battery & Volts $(\mathrm{V})$ \\
\hline$Q$ & Charge & Coulombs $(\mathrm{C})$ \\
\hline$T$ & Time & Seconds $(\mathrm{sec})$ \\
\hline
\end{tabular}




\section{REFERENCES}

Larson, Ron, Robert Hosteteler, and Bruce Edwards. Calculus: Early Transcendental functions. New York: Houghton Mifflin Company, 2007.

Raymond A., Serway, and John W. Jewett, Jr.. Physics: for Scientist and Engineers. Belmont, Ca: David Harris, 2005

Koehler, Kenneth R. "Capacitors and RC Circuits". College Physics for Students of Biology and Chemistry. 04/28/2010 < College Physics for Students of Biology and Chemistry $>$.

Bill Sheets and Rudolf F. Graf, "RC Timers and Timing Circuits." North Country Radio. 04/27/10<http://www.northcountryradio.com/PDFs/column008.pdf $>$. 


\section{APPENDIX}

\section{GRAPH 1.1}

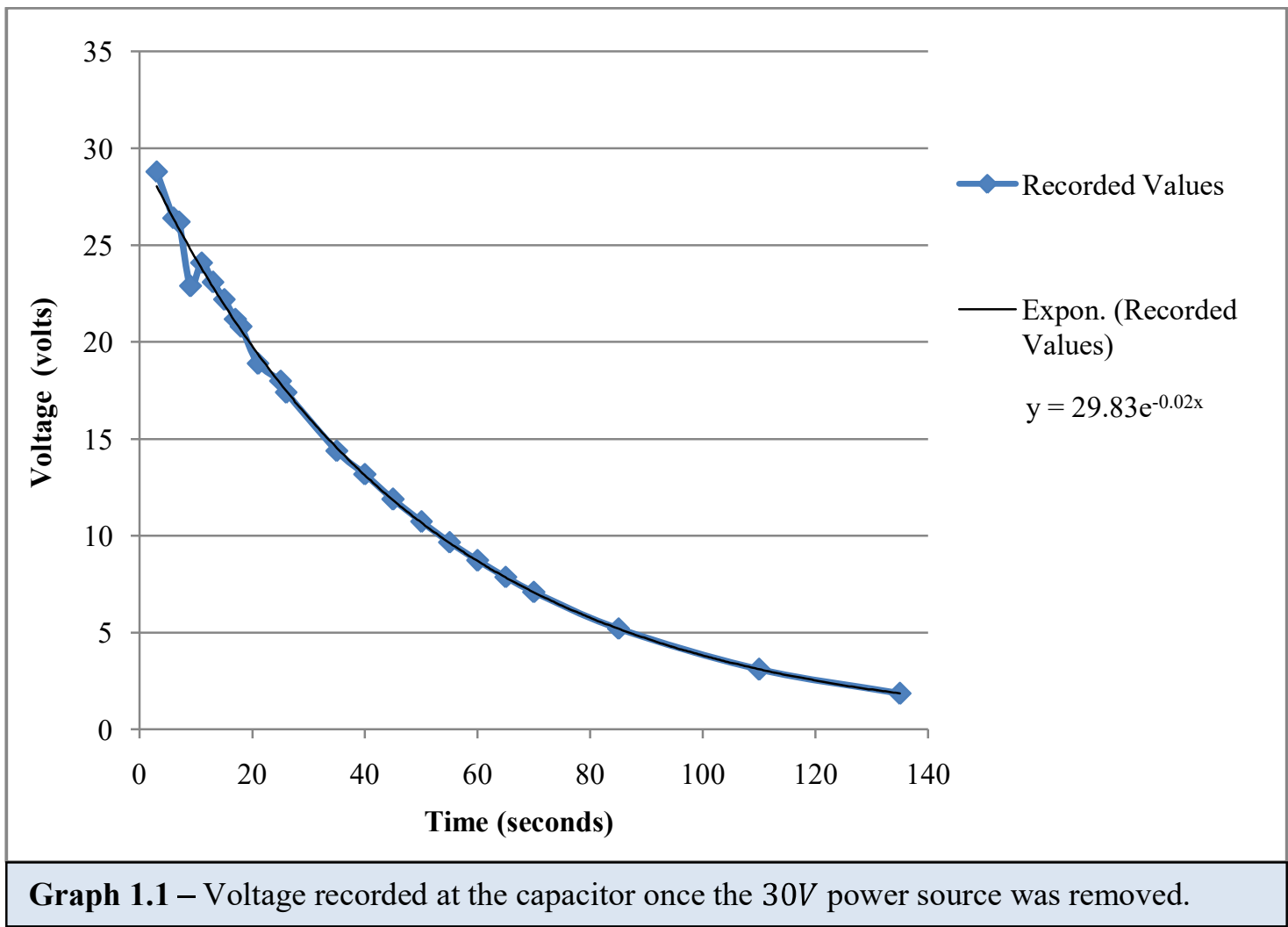

TABLE 1.2

\begin{tabular}{|cl|}
\hline Time & \multicolumn{1}{c|}{ Voltage } \\
\hline 3 & 28.79984 \\
\hline 6 & 26.39976 \\
\hline 7 & 26.19992 \\
\hline 9 & 22.90024 \\
\hline 11 & 24.10016 \\
\hline 13 & 23.09989 \\
\hline 15 & 22.19985 \\
\hline 17 & 21.2002 \\
\hline 18 & 20.79984 \\
\hline 21 & 18.89992 \\
\hline 25 & 17.9999 \\
\hline 26 & 17.40003 \\
\hline
\end{tabular}

\begin{tabular}{|cc|}
\hline Time & Voltage \\
\hline 35 & 14.39992 \\
\hline 40 & 13.18014 \\
\hline 45 & 11.88995 \\
\hline 50 & 10.73001 \\
\hline 55 & 9.670079 \\
\hline 60 & 8.729915 \\
\hline 65 & 7.869914 \\
\hline 70 & 7.100027 \\
\hline 85 & 5.210027 \\
\hline 110 & 3.109997 \\
\hline 135 & 1.859987 \\
\hline
\end{tabular}




\section{GRAPH 2.1}

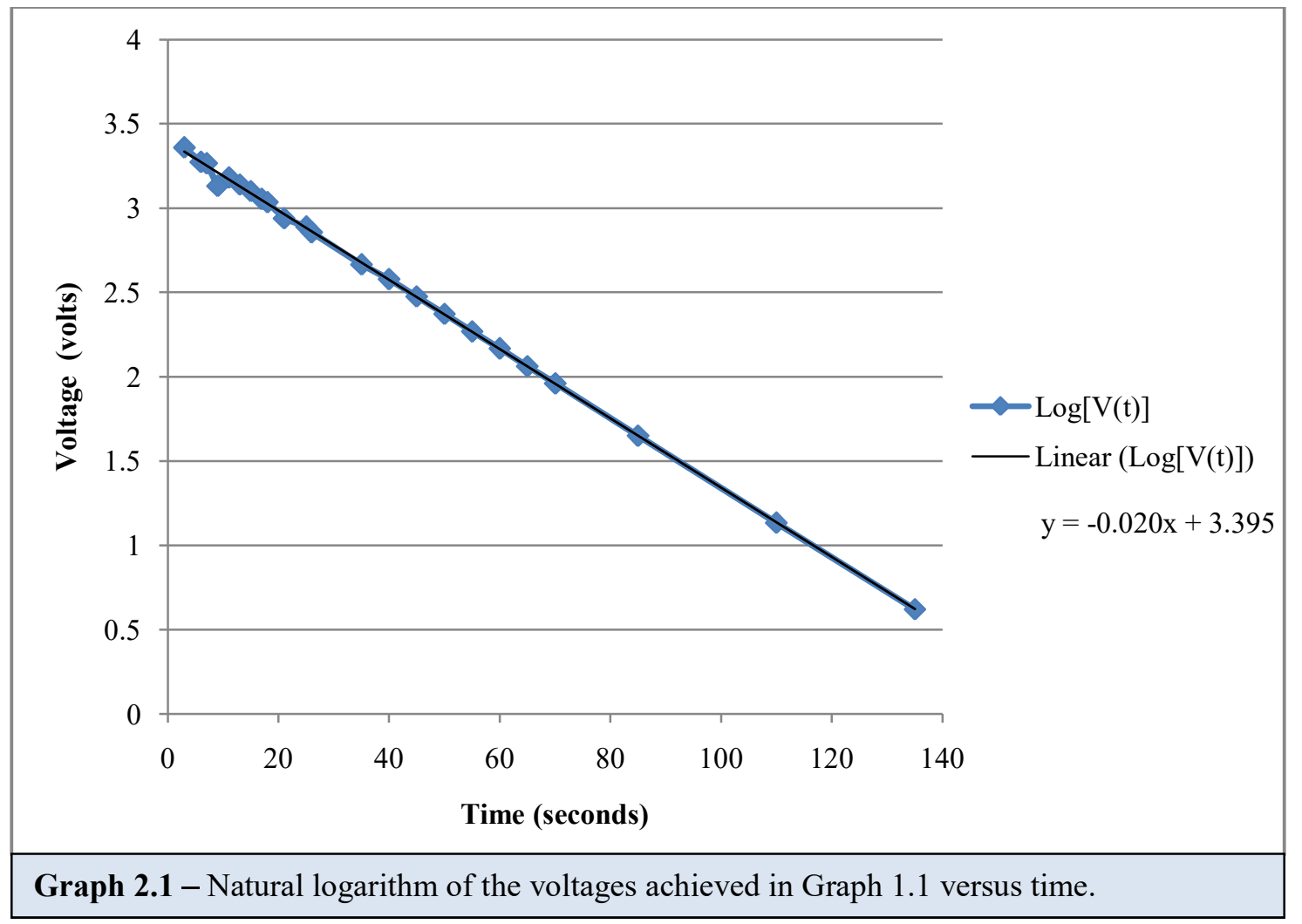

TABLE 2.2

\begin{tabular}{|c|c|}
\hline Time & Voltage \\
\hline 3 & 3.36037 \\
\hline 6 & 3.273355 \\
\hline 7 & 3.265756 \\
\hline 9 & 3.131147 \\
\hline 11 & 3.182218 \\
\hline 13 & 3.139828 \\
\hline 15 & 3.100086 \\
\hline 17 & 3.054011 \\
\hline 18 & 3.034945 \\
\hline 21 & 2.939158 \\
\hline 25 & 2.890366 \\
\hline 26 & 2.856472 \\
\hline
\end{tabular}

\begin{tabular}{|c|c|}
\hline Time & Voltage \\
\hline 35 & 2.667223 \\
\hline 40 & 2.578711 \\
\hline 45 & 2.475694 \\
\hline 50 & 2.373044 \\
\hline 55 & 2.269036 \\
\hline 60 & 2.166756 \\
\hline 65 & 2.063047 \\
\hline 70 & 1.960099 \\
\hline 85 & 1.650585 \\
\hline 110 & 1.134622 \\
\hline 135 & 0.620569 \\
\hline
\end{tabular}

